\title{
Assistência entre a proteção à dignidade humana e a desresponsabilização estatal
}

Assistance between the protection of human dignity and state disengagement

\author{
Ana Claudia Pereira Simões Lima* \\ Raquel de Matos Lopes Gentilli**
}

\begin{abstract}
Resumo:
As estratégias neoliberais estão reiteradamente buscando novas opções para a utilização de mecanismos democráticos a favor dos interesses capitalistas, visando reconstruir suas formas de dominação. Na expectativa de manutenção de hegemonia, tais estratégias podem fragilizar toda concepção teórica de proteção social, legalmente conquistada, quando utilizadas organizações não governamentais para a desresponsabilização estatal. O presente artigo discute, a partir dos dados oficiais e paradigmas teóricos existentes, a atuação da rede privada de assistência social e as consequências do hibridismo legal relacionadas ao financiamento público, objetivando provocar reflexões sobre as contradições que envolvem benefícios e os danos da atuação das entidades no atendimento socioassistencial.
\end{abstract}

Palavras-chave: Assistência social. Sistema Único de Assistência Social. Entidades sem fins lucrativos. Terceiro setor.

\begin{abstract}
:
The neoliberal strategies are consistently seeking new options for use of democratic mechanisms as legitimate social achievements in favor of capitalist interests, the prospect of rebuilding their ways of driving. In anticipation of maintaining hegemony can be undermined an entire theoretical conception of social protection, legally earned, used when non-governmental organizations in support of state disengagement. This article seeks to contextualize official data on performance of the private network of social assistance, the legal consequences hybridity and theoretical paradigms in view of provoking reflections on the dichotomy benefits and harms of the performance of the entities of social assistance service.
\end{abstract}

Keywords: Social assistance. Unified Social Assistance Nonprofits. Private network. Nonprofits of public right. Third sector.

\footnotetext{
* Mestre em Políticas Públicas e Desenvolvimento Local pela Escola Superior de Ciências da Santa Casa de Misericórdia de Vitória - EMESCAM, E-mail: anaclaudia@ativoconsultoria-es.com.br.

*- Mestre em Ciências Sociais e Doutora em Serviço Social, ambos pela Pontifícia Universidade Católica de São Paulo. E-mail: raquel.gentilli@emescam.br.
} 


\section{Introdução}

A Assistência Social no Brasil consiste em um conjunto de ações, de interesse público, planejadas de forma articulada e hierarquizada, caracterizada por serviços, projetos, programas e benefícios, incondicionalmente disponíveis a todo cidadão que dela necessitar, fazendo parte do tripé da Seguridade Social.

Nesse campo, destacam-se as organizações não governamentais criadas para realizar práticas afirmativas pela inclusão social, direitos humanos, paz e segurança humana, relações étnico-raciais, ética e juventude no sentido de garantir os direitos fundamentais, incentivar o desenvolvimento de expressões de sociabilidades excluídas, refletir sobre valores coletivos, enfrentar estigmas, estereótipos sociais e as mais diversas formas de preconceitos que agravam os processos de exclusão social.

Em torno de entidades dessa natureza e de suas funções públicas na relação com o Estado e com as classes subalternas, existe um grande debate sobre as particularidades quando o tema envolve "entidades sem fins lucrativos" ou "filantrópicas". Na assistência social, tais organizações são chamadas a atuar como parceiras do Estado, constituindo retaguarda para ações especializadas de assistência social, como é o caso dos serviços de acolhimento para crianças e adolescentes, e vem recebendo subsídios, subvenções e isenções fiscais, funcionando como partícipe do Estado por meio da gestão compartilhada.

Nesse sentido, o presente artigo tem como objetivo refletir - a partir de uma breve pesquisa bibliográfica e documental -, sobre a natureza das atuais entidades assistenciais em seus aspectos legais relacionados ao financiamento público, evidenciando um dos fatores constituintes das forças motrizes de manutenção do caráter tradicional das ações do Estado na assistência social, que é a terceirização.

\section{O Sistema Único de Assistência Social}

A Constituição Brasileira de 1988 (BRASIL, 1988) abre uma nova perspectiva para a forma de reconhecimento da cidadania no Brasil, tomada como direito universal e dever do Estado, o que contribui para a consagração das argumentações em torno da consolidação da assistência social como política pública, situação que se consagra a partir 
da definição de legislação específica, imprescindível à uniformização dos conceitos, das diretrizes e das condições de exercício ao acesso aos direitos sociais para todos os cidadãos.

Essa garantia ganha contornos factíveis com a publicação da Lei Orgânica de Assistência Social (LOAS), e com ela a previsão para a criação de um sistema descentralizado e participativo, que é o Sistema Único de Assistência Social - SUAS, cuja deliberação para implementação aconteceu em 2003 na IV Conferência Nacional de Assistência Social. A partir daí, outras importantes orientações dela decorreram, como é o caso da Resolução no 145/2004 (BRASIL, 2004) do Conselho Nacional de Assistência Social (CNAS), que aprovou a Política Nacional de Assistência Social (PNAS) e seu texto final, focada, naquele momento, em três perspectivas de atuação: defesa do direito à renda, à segurança alimentar e à assistência social.

Como forma de operacionalizar a participação popular no Sistema SUAS, conforme previsto na LOAS, diretriz prevista na Norma Operacional SUAS, em seu capítulo 1 (BRASIL, 2005, p. 11-16) preconizou-se além de participação de movimentos sociais, a construção de parcerias com entidades sem fins lucrativos, classificadas legalmente para determinados fins nos termos e condições daquela Lei. Nesse sentido, as entidades sem fins lucrativos passaram a poder atuar legalmente no Sistema da Assistência Social em atividades de atendimento direto aos usuários (Resolução CNAS 109/2009) e em atividades de assessoramento e/ou de defesa e garantias de direitos (Resolução CNAS 27/2011) (BRASIL, 2009c; 2011).

As referidas entidades que praticam atividades de atendimento e atuam como integrantes do Sistema SUAS (segundo o disposto na LOAS, art. 6으, parágrafo 2ㅇ) podem realizar atividades sob justificativa de constituírem ação complementar às dos serviços públicos socioassistenciais, passando a ser denominadas entidades da rede privada de assistência social (BRASIL, 1993b). Por definição da Política Nacional de Assistência Social (PNAS), em se tratando da rede pública, os serviços podem ser oferecidos pelas Redes de Proteção Social Básica e Especial da Assistência Social, por meio dos Centros de Referência de Assistência Social (CRAS) e Centros Especializados de Assistência Social (CREAS), redefinindo, dessa forma, os novos parâmetros, processos e procedimentos relativos ao Sistema de Proteção Social Brasileiro. 
Para atuação complementar por meio da rede privada, de maneira que oferecesse retaguarda às situações consideradas mais complexas ou com demandas excessivas, surgiu a previsão legal de atuação das entidades privadas sem fins lucrativos. 0 artigo 10 da LOAS já previa que o provimento dos mínimos sociais aconteceria mediante um conjunto integrado de ações que também contaria com iniciativas da sociedade. Nessa perspectiva, o artigo 3 , conjugado com o parágrafo $2 \circ$ do artigo 60 da mesma legislação, inseriram as entidades sem fins lucrativos como integrantes do SUAS, determinando que poderiam realizar inclusive atendimentos socioassistenciais, bem como assessoramento e defesa e garantia de direitos, configurando a forma de atuação da rede privada de assistência social no Brasil.

O Censo SUAS (BRASIL, 2010a) já estava sendo realizado anualmente desde o ano de 2007, operacionalizado pela Secretaria Nacional de Assistência Social do Ministério do Desenvolvimento Social e Combate à Fome (MDS). Em 2010, passou a incluir as atividades das entidades privadas de assistência social na pesquisa das ações desenvolvidas nos estados e municípios, tendo em vista subsidiar a construção e a manutenção de indicadores de monitoramento e avaliação para a Política Nacional de Assistência Social (PNAS). O registro de informações sobre a atuação da Rede Privada de Assistência Social incluiu, assim, as entidades de assistência social que recebem recursos públicos, prestam serviços e desenvolvem ações específicas no campo da assistência social, atuando como parceiras do poder público na implementação de políticas nessa área e que tinham "celebrado convênio e outras formas de ajuste com os municípios", alcançando, também, as entidades certificadas pelo MDS em 2010 (BRASIL, 2010a).

Para a realização dessa atuação complementar, as entidades privadas precisaram se inscrever formalmente no Sistema SUAS para apresentar suas condições estruturais de forma a demonstrar que poderiam realizar amplamente suas atividades de maneira eficaz. Tal procedimento, determinado pela Resolução no 109/2009 do Conselho Nacional de Assistência Social, possibilitaria que as entidades pudessem ser analisadas, comprovadas, atestadas, acompanhadas, avaliadas e fiscalizadas pelos Conselhos Municipais e Estaduais, bem como pelo Conselho Nacional de Assistência Social.

Os membros dos Conselhos Municipais de Assistência Social (CMAS) passaram a ter, por meio das orientações das diretrizes dispostas na Resolução CNAS 16/2010 (BRASIL, 
2010b), a competência de atestar as condições das entidades sem fins lucrativos e habilitálas ao atendimento a usuários da assistência social por meio de serviços socioassistenciais, previstos em projetos e programas previamente apresentados aos CMAS de seus respectivos municípios para serem submetidos à aprovação.

Tais procedimentos deram origem à legitimação pública de capacidade técnicaestrutural da rede privada para a realização de ações credenciadas, inclusive habilitandoas à captação de recursos públicos e de solicitação de isenções tributárias pelo fato de estarem, inicialmente, participando do financiamento da Seguridade Social.

A legislação é explícita ao afirmar que, além das entidades de atendimento da rede privada de assistência social, fazem parte também da composição do Sistema Único da Assistência Social aquelas entidades com funções de realização de ações de educação social e participação política que realizem atividades de assessoramento e/ou de defesa e garantias de direitos (Resolução CNAS 27/2011) (BRASIL, 2011).

O panorama da atuação da rede privada de assistência social, traçado pelo Censo SUAS 2010 indica que 9.398 entidades privadas atuam na assistência social no Brasil, sendo que $55 \%$ se concentram na Região Sudeste. Do total das entidades mapeadas, $10,5 \%$ podem atuar em outros municípios, além daqueles onde está situada sua sede.

Quanto ao funcionamento, $42,7 \%$ possuem 40 horas de jornada semanal com 8 horas diárias de atividades, e 25\% declararam funcionar ininterruptamente. Apesar disso, verificou-se que a busca ativa não se constitui em um instrumento de trabalho relevante na forma de atendimento, pois $85,1 \%$ das entidades atendem aos usuários somente a partir da sua procura espontânea.

A relevância dos parceiros privados para a prestação de serviços públicos de assistência social fica bastante evidente quando é analisado o volume de encaminhamentos de usuários para as entidades da rede privada: $53,4 \%$ das entidades recebem encaminhamentos feitos pelos Centros de Referência de Assistência Social (CRAS) e 53,7\% recebem usuários encaminhados por outra política pública e/ou sistema de garantia de direitos.

Caracterizando a forma de atuação das entidades da rede privada, o Censo SUAS identificou que $90,2 \%$ delas atuam no atendimento socioassistencial; $53,9 \%$ atuam na 
defesa e garantia de direitos e $41,4 \%$ atuam com assessoramento, sendo que uma mesma entidade pode ter mais de uma área de atuação simultaneamente.

Apesar de declararem que atuam em mais de uma frente, os dados do Censo SUAS já demonstravam em 2010 uma tendência da Rede Privada atuar preferencialmente no atendimento direto aos usuários da assistência social, seja pela procura espontânea, seja por encaminhamentos da rede socioassistencial pública, de serviços de saúde e outros, configurando uma terceirização de parte dos serviços públicos de assistência social.

\section{Natureza jurídica das entidades sem fins lucrativos}

O Estado é objeto de disputa de todas as classes sociais e isso também se aplica à disputa pelo fundo público e pelo financiamento da assistência social, mediada pelas organizações não governamentais, que ganham relevo com a gestão compartilhada ao se estabelecerem enquanto parceiros representando a sociedade civil na prestação de serviços socioassistenciais.

Nesses termos, entende-se como fundamental um olhar crítico em relação à parceria público-privada e para atuação desse segmento na execução de políticas assistenciais. Tais reflexões que aqui se esboçam, de um lado, pontuam fragilidades ocasionadas pela legislação que regulamenta tais organizações, e de outro, ao histórico recente da atuação do Estado no campo da assistência social, seguindo as diretrizes pautadas pela estratégia neoliberal, que privilegia interesses econômicos, em detrimento da reprodução da força de trabalho e da organização da sociedade civil como um todo.

O primeiro aspecto será abordado a partir de uma reflexão comparativa entre a legislação que regulamenta as autarquias públicas (figura jurídica criadas em 1967) e a legislação atual que regulamenta as organizações privadas com finalidades públicas. Desta comparação, pode-se observar um novo elemento que dá volume a inúmeros outros argumentos da corrente contrária à participação das entidades sem fins lucrativos na rede socioassistencial.

Apesar de ter sido criada com outra lógica, outra finalidade, outra essência e outras diretrizes, a autarquia (que se constitui pessoa jurídica de direito público interno no âmbito da administração pública indireta do Estado), e regulamentada pelo Decreto-Lei 200/67 
que determina que sua criação decorra de uma lei, oferece alguns elementos comparativos para a análise da recente legislação que regulamenta a assistência social.

Em comparação com a Lei 10.406/2002 (artigos 53 ao 69), fundamento legal que determina diretrizes para funcionamento de entidades privadas sem fins lucrativos (BRASIL, 2002a), o Decreto-Lei 200/67 (BRASIL, 1967), que regulamenta os serviços prestados pelas autarquias, é muito mais rigoroso, apesar de ter sido esse tipo jurídico também idealizado e regulamentado para executar atividades e serviços que são prerrogativas da administração pública, assim como vem atuando a maioria das entidades da rede privada de assistência social.

Segundo o Decreto-Lei 200/67, as autarquias possuem algumas características como: terem personalidade jurídica pública, finalidades específicas e capacidade de autogestão; não possuírem capacidade política; terem patrimônio próprio e especialização dos fins; estão impedidas de exercerem atividades das quais não são especialistas e estão sujeitas ao controle e tutela do Estado; destinam-se a realizar serviços públicos descentralizados; seus bens são considerados públicos; possuem recursos humanos remunerados; podem praticar atos privados, desde que regulados por judiciário e processo civil comum.

Do ponto de vista da responsabilização pública, as autarquias assumem responsabilidade civil por danos causados a terceiros; possuem imunidades tributárias para a realização de suas atividades fins; não possuem imunidade tributária sobre atividades não fins; são responsáveis por seus atos não envolvendo a esfera pública a que estiverem ligadas; suas receitas são próprias, mas tuteladas pelo Estado; existem várias espécies e algumas podem ser certificadas com competências especiais; podem ser extintas de ofício se forem ineficientes (se ficarem inativas ou se realizarem atividades não previstas na lei que as instituiu); terão extinguido os cargos considerados desnecessários à prestação dos serviços fins; estão obrigatoriamente sujeitas à processo de licitação (BRASIL, 1967).

Já as organizações do chamado Terceiro Setor ou Organizações Não Governamentais, ou seja, também as entidades que prestam serviços socioassistenciais componentes da rede privada de assistência social, foram idealizadas para executar atividades e serviços que deveriam ser prerrogativas da administração pública, mas que a elas foram delegados para facilitar as relações entre a estrutura burocrática do Estado e a prestação dos serviços, no caso das entidades que optaram pela atuação na modalidade "atendimento". Nesse 
sentido, foram concebidas para que prestassem serviços diretos aos usuários da assistência social pela sociedade civil organizada ou organização não governamental.

Em termos legais, resumem-se a duas espécies de entidades: associações ou fundações. Juridicamente falando, quase todas as entidades privadas sem fins lucrativos estão dentre esses dois tipos jurídicos. A exceção fica para os partidos políticos e para as instituições religiosas, que, embora sejam de natureza privada, ficam fora daquela classificação devido a outros dispositivos legais (BRASIL, 2002a).

Ambas, associações e fundações são regidas pelo direito privado e, por consequência, regulamentadas com regras estabelecidas no Código Civil Brasileiro e não estão sujeitas a todos os mecanismos de controle público existentes para as ações da administração direta do Estado.

As ONGs, como já citado, são regidas legalmente pela seguinte categorização: associações e fundações. As associações são definidas como a união de pessoas que se organizam para fins não econômicos, segundo art. 53 da Lei 10.406/2002. Já as fundações privadas, regidas pela mesma lei, em seu art. 62 , são definidas como entidades também de direito privado, porém, só podem ser constituídas quando um instituidor fizer doação de bens livres por meio de escritura pública ou testamento, podendo declarar como será administrado e qual o fim desse patrimônio. A regra também é válida para entidades sem fins lucrativas da rede privada de assistência social, referentes ao SUAS, cuja a natureza jurídica caberá em uma das duas categorias citadas.

A mais importante característica dessas organizações é que não precisam ser criadas por lei (como as autarquias). Outras características, que lhes são peculiares, é que tais entidades, associações e fundações devem ser: pessoas jurídicas de natureza privada; de finalidade não lucrativa; com gestão em torno de uma causa social previamente definida no estatuto social, cujos órgãos de administração devem gerir suas receitas e patrimônio para alcance dos objetivos sociais. Na maioria dos casos, possuem objetivos de interesse público, tais como educação, cultura, assistência social, proteção do meio ambiente e outros; e em outros casos, algumas associações podem ter objetivos de interesse coletivo, tais como as associações de moradores, associações de profissionais, sindicatos e outros.

Em ambos os tipos jurídicos, a finalidade é a gestão privada de recursos e patrimônio para atendimento de demandas da população ou parcela dela, por meio, normalmente, de 
captação de recursos provenientes da apresentação de projetos sociais e seus custos a empresas privadas, órgãos públicos ou do autofinanciamento por meio de seus associados ou instituidores.

Tais receitas são consideradas "atividades próprias de instituições sem fins lucrativos"; também conhecidas como "receitas de atividades fins". Ou seja, constitui-se no meio natural de manutenção desse tipo de entidade, que pela lógica legal não foi originada para ter como principal fonte de renda a prestação de serviços como contrapartida ou pelos quais se cobre para sua execução; pois esses configuram atividade econômica e tais entidades foram definidas pelo artigo 53 da Lei 10.406 de 2002 como "sem fins econômicos".

A Instrução Normativa da Receita Federal do Brasil, no 247 do ano de 2002, ratifica em seu artigo 47, parágrafo $2^{\circ}$, o que este órgão considera como receita de atividade essencial das entidades sem fins lucrativos. Observa-se:

$\S 2$ 2․ Consideram-se receitas derivadas das atividades próprias somente aquelas decorrentes de contribuições, doações, anuidades ou mensalidades fixadas por lei, assembleia ou estatuto, recebidas de associados ou mantenedores, sem caráter contraprestacional direto, destinadas ao seu custeio e ao desenvolvimento dos seus objetivos sociais (BRASIL, 2002b).

No caso da Política Pública de Assistência Social, o artigo 6으 da LOAS, ao estabelecer os objetivos da proteção social, conferiu a ela o caráter não contributivo. Como as entidades da rede privada são componentes do SUAS, devem atender ao mesmo princípio da garantia da não contribuição do usuário como condição de acesso aos serviços, projetos e programas por esse oferecidos, posição ratificada pelo artigo 18 da Lei 12.101/2009 (BRASIL, 2009a), que determina expressamente que os serviços oferecidos pela rede privada de assistência social devem ter caráter gratuito.

Em resumo, no aspecto legal e ideológico, as associações e fundações que trabalham em prol de atividades de interesse público, tais como as entidades privadas nos atendimentos de assistência social, tiveram origem para prestar serviços gratuitamente aos seus beneficiários e sobreviver financeiramente de recursos de terceiros, não beneficiários diretos, tais como empresas, pessoas físicas, órgãos públicos e outros. 
Analisando as práticas adotadas pelas entidades que prestam serviços públicos em parcerias público-privada, fica a impressão que o tipo jurídico criado para executar serviços públicos pela sociedade civil, ou seja, as entidades sem fins lucrativos têm se desenvolvido de forma inadequada às finalidades originais, na medida em que não possuem independência do Estado.

Por outro lado, pode-se pensar também que o Estado, utilizando-se desse dispositivo legal, transfere para a esfera privada aquelas ações que seriam de sua responsabilidade administrativa, com graves consequências à prestação do serviço em si e aos usuários que deveriam ser beneficiados. Pela previsão legal específica, tais entidades - para viabilizarem a prestação de serviços públicos -, deveriam ter certa independência, autonomia e segurança jurídica no trato com a coisa pública, pois, comparadas às autarquias, estas últimas têm autogestão, patrimônio próprio e estão sujeitas ao controle do Estado.

A impressão que se tem nesse cenário é que as práticas neoliberais encontraram mais uma vez uma forma de reinventar algo já existente, travestindo um tipo jurídico, (as organizações não governamentais) com adereços de outro tipo, parecidas ao tipo jurídico das autarquias, simplificando o controle público sobre elas como uma maneira de criar o que poderíamos chamar de autarquias desburocratizadas.

Numa análise comparativa entre a legislação, que rege autarquias, e as organizações não governamentais, que prestam serviços públicos terceirizados e projetando as diferenças encontradas para o âmbito da parceria público-privada, percebemos que parte dos procedimentos válidos para as ONGs são semelhantes aos que foram definidos por lei para o modelo jurídico de autarquia. Entretanto, os procedimentos previstos para as autarquias, que garantiriam maior transparência às suas ações, não são obrigatórios na legislação de regência das ONGs, já que essas estão sob o controle do Novo Código Civil.

Visto por esse ângulo, fica evidente que é "mais fácil" firmar parcerias com ONGs que prestar serviços diretamente pela administração pública, prerrogativa legal do Estado, ou mesmo criar autarquias para a prestação de serviços públicos, pois a ausência e procedimentos mais rígidos de controle sobre as ONGs torna-os mais vulneráveis e sujeitas à manipulação de interesses os mais diversos na relação da parceria público-privada.

A característica híbrida que adotaram as entidades de natureza privada sem fins lucrativos que terceirizam serviços públicos são, em parte, juridicamente, muito parecidas 
com as autarquias porque possuem muitas de suas características legais. De outra parte, já parecem bem diferentes, pois não têm certas obrigações legais.

Para uma reflexão crítica sobre esse "hibridismo" e sua finalidade e consequência, é necessário organizar as características dos dois tipos jurídicos, determinadas segundo a legislação de regência de ambos: autarquias e ONGs. Foram levados em consideração 23 características passíveis de comparação. No resultado, constatou-se que em 14 delas, ou seja, $60,87 \%$ dos itens demonstram semelhança entre as autarquias e as entidades sem fins lucrativos criadas para terceirização de serviços públicos.

Isto significa dizer que, neste ponto da análise, se ambas trabalhassem com recursos públicos essencialmente, as ONGs seriam semelhantes às autarquias, não fazendo diferença, do ponto de vista do beneficiário, a criação de uma autarquia ou estabelecimento de parceria com ONG para prestar os serviços necessários.

A análise fica mais interessante quando demonstrado que dentre as 9 características distintas, ou seja, aquelas regras exigidas para autarquias e dispensadas para entidades privadas sem fins lucrativos, a maioria delas, $88,89 \%$, seria instrumentos concretos para proteção da população brasileira contra eventual atuação ineficaz das "entidades sem fins lucrativos". Neste ponto da análise, as diferenças entre autarquias e ONGs ficam evidentes nos aspectos de manipulação das ações, fragilidades no controle social e da fiscalização. Dependendo da intenção, fará muita diferença a opção por criar uma autarquia ou firmar parceria com uma ONG.

São características das autarquias segundo legislação (Decreto 200/67):

1. São criadas por lei;

2. Têm personalidade jurídica pública;

3. Têm finalidades específicas;

4. A forma de criação e extinção e suas competências são definidas por lei;

5. Possuem capacidade de autogestão;

6. Não têm capacidade política, ou seja, não podem criar o próprio direito que Ihes rege, seguem a legislação de regência;

7. Têm patrimônio próprio;

8. Têm especialização dos fins (objetivos claros); 
9. Estão impedidas de exercerem atividades diversas das quais não sejam especialistas;

10. Estão sujeitas ao controle e tutela do Estado;

11. Realiza serviço público descentralizado;

12. Seus bens são considerados públicos;

13. Recursos humanos remunerados;

14. Podem praticar atos privados (atípicos) regulados pelo judiciário e processo civil comum;

15. Há responsabilidade civil pelos dados causados a terceiros;

16. Possuem imunidade tributária na realização de atividades fins;

17. Não possuem imunidade tributária na realização de atividades não ligadas às finalidades essenciais;

18. São responsáveis por seus atos não envolvendo a esfera pública a que estiverem ligadas;

19. Receita própria, mas tutelada pelo Estado;

20. Existem várias espécies e algumas qualificadas com competências especiais;

21. Se desempenharem atividades já satisfatórias pela rede privada, se ficarem inativas ou se exercerem atividades não previstas serão extintas;

22. Cargos não necessários para a prestação de serviços serão extintos;

23. Estão sujeitos ao processo de licitação (BRASIL, 1967).

São características previstas para ONGs (lei 10.406/2002, Lei 9.790/09, C.F/88 e Lei 8.666/93) e que também são comuns às autarquias:

1. Têm finalidades específicas;

2. Possuem capacidade de autogestão;

3. Não têm capacidade política, ou seja, não podem criar o próprio direito que Ihes rege, seguem a legislação de regência;

4. Têm patrimônio próprio;

5. Têm especialização dos fins (objetivos claros);

6. Realiza serviço público descentralizado;

7. Recursos humanos remunerados; 
8. Podem praticar atos privados (atípicos) regulados pelo judiciário e processo civil comum;

9. Há responsabilidade civil pelos dados causados a terceiros;

10. Possuem imunidade tributária na realização de atividades fins;

11. Não possuem imunidade tributária na realização de atividades não ligadas às finalidades essenciais;

12. São responsáveis por seus atos não envolvendo a esfera pública a que estiverem ligadas;

13. Existem várias espécies e algumas qualificadas com competências especiais;

14. Estão sujeitos ao processo de licitação (BRASIL, 1993a; 1988; 2002a; 2009b).

São características previstas para autarquias e dispensadas para ONGs:

1. São criadas por lei;

2. Têm personalidade jurídica pública;

3. A forma de criação e extinção e suas competências são definidas por lei;

4. Estão impedidas de exercerem atividades diversas das quais não sejam especialistas;

5. Estão sujeitas ao controle e tutela do Estado;

6. Seus bens são considerados públicos;

7. Receita própria, mas tutelada pelo Estado;

8. Se desempenharem atividades já satisfatórias pela rede privada, se ficarem inativas ou se exercerem atividades não previstas serão extintas;

9. Cargos não necessários para a prestação de serviços serão extintos.

As ONGs são criadas livremente e não por lei, basta registro de estatuto no cartório; têm personalidade jurídica privada; criação, extinção e competências não dependem de lei e sim do estatuto social; podem exercer várias atividades sem especialização exigida por lei; devem seguir princípios morais e éticos mas não são controladas pelo Estado efetivamente; seus bens são privados porém com fins públicos; não há regime de fiscalização pública para associações, existindo apenas para fundações; mesmo que desempenhem atividades já satisfatórias pela rede privada ou se ficarem inativas ou se exercerem atividades não previstas nos estatutos, não serão extintas; não há controle do 
Estado e nem exigência legal de extinção dos cargos não necessários para a prestação de serviços, mesmo quando remunerados com recursos públicos.

\section{Controvérsias teóricas em relação à atuação das ONGs}

Nos debates atuais sobre Organizações Não Governamentais e Terceiro Setor, é comum encontrar o emprego de conceitos de forma distinta de seus empregos originais. Essa nova maneira de se referir à filantropia vem reconstituindo um campo de debates teóricos, que apontam algumas divergências importantes no campo das disputas políticas.

Um desses conceitos tem sido o de sociedade civil transformado num conceito, não raro, utilizado para legitimar certas práticas associadas às entidades que gravitam em torno das ações assistenciais, ditas entidades sem fins lucrativos, e que foram constituídas para a prestação de serviços públicos nos espaços da Política Nacional de Assistência Social em parceria com o Estado, atuantes na rede privada de assistência social, realizando atendimentos associados aos Centros de Referência de Assistência Social (CRAS) e aos Centros de Referência Especializados de Assistência Social (CREAS).

Aquilo que teria sido criado para compor um mosaico de serviços públicos e privados para enfrentar a questão da pobreza no Brasil vem revelando limites de atuação preocupantes social e politicamente. As entidades sem fins lucrativos estão dirigindo seu foco para a realização de atendimentos de assistência social, contribuindo significativamente para que a gestão pública acabe transferindo parte de suas responsabilidades para com a assistência social para a esfera privada, muitas vezes, apoiada em financiamento público.

As pesquisas de campo e debates teóricos revelam que, um grande volume de ONGs hoje existentes funciona não mais como um terceiro setor independente do Estado, mas como organizações que participam da estratégia de desresponsabilização desse sobre a pobreza gerada pela política econômica em curso, no mínimo problemática e acrítica.

O Ministério do Desenvolvimento Social e Combate à Fome considera que a rede privada de assistência social pode ou não realizar suas funções por meio de recursos públicos, sendo que denomina as que recebem verba pública de "entidades conveniadas", conforme relato da Secretaria Nacional de Assistência Social (BRASIL, 2010a, p. 126). 
A mesma linha de classificação é seguida por autores clássicos "até hoje a ação estatal no campo da assistência social pública se dilui entre o aparato próprio e o chamado conveniado, ou indireto" (SPOSATI et al., 2012, p. 89).

Tarefas socioassistenciais, destinadas à amenização das desigualdades sociais, realizadas por meio das chamadas "parcerias público-privadas", e que visem evitar o agravamento da questão social, podem ter consequências benéficas na lógica do processo de legitimação de governos e governantes e na redução das tensões políticas no âmbito do sistema público de atendimento socioassistencial.

Tal processo, entretanto, traz como consequência a desresponsabilização da ação direta do Estado, tornando-as pulverizadas e assistemáticas; apenas uma estratégia de apaziguamento das tensões sobre a ordem social, sem constituir intervenção técnicas mais consistentes e duradouras, com acúmulo de saber e massa crítica para enfrentar as questões cotidianas do fazer profissional.

O papel das entidades sem fins lucrativos no Brasil tem sido ambivalente e cheio de contradições, mas, apesar disso, a ação de tais entidades acaba tendo consequências sociais para assegurar a sobrevivência da população. Yazbek $(2004$, p. 22) aponta como o conjunto de dificuldades, pelas quais passa a população de baixa renda pressiona nessa direção:

Marcados por um conjunto de carências, desqualificados pelas condições em que vivem e trabalham, enfrentando cotidianamente o confisco de seus direitos mais elementares, buscam, na prestação de serviços sociais e na filantropia privada, alternativas para sobreviver.

Os motivos que levam a assistência social brasileira a trabalhar na ambiguidade, oscilando entre a implementação prática de algumas medidas de proteção social previstas na LOAS por meio de políticas públicas e de atuação desarticulada e assistemática, porém, emergencial, têm sido uma forma de se construir, segundo Mishra (apud YAZBEK, 2004), uma espécie de rede de segurança para a assistência social.

A atuação das entidades da rede privada, crescente a partir dos anos 1990, foi marcada pela incipiência de um sistema de proteção social, cuja ineficiência está associada à direção compensatória de ações erráticas, tímidas e, sobretudo, marcada por alternativas seletivas e privatistas, estratégias de uma política contaminada pelo neoliberalismo. 
Apesar de ser inegável a manutenção do clientelismo por parte de algumas entidades da rede privada, há de se considerar que a participação de tais entidades na rede de socioatendimento foi viabilizada pela própria estrutura prevista pela LOAS.

Com a unificação organizacional do Sistema Único da Assistência Social no país, a participação das entidades privadas passa a compor os esforços de viabilização da política como parte do sistema descentralizado e participativo da Assistência Social. Há de se considerar ainda que as entidades filantrópicas têm sido uma das únicas opções, em muitas circunstâncias, para muitos brasileiros que tentam acessar serviços e projetos de assistência social. Yazbek (2004) vai além, chama a atenção para a função de mediação tradicional que as entidades de assistência social desenvolveram no país. Para a autora, as entidades do setor filantrópico, acompanhadas das formas filantrópicas, caritativas e benemerentes de socorrer os pobres constituíram as mediações fundamentais para o exercício da assistência social, e não apenas no Brasil.

Para além dessa realidade de apoio governamental na rede privada, existe ainda o cerne da questão referente à própria concepção da Política Nacional de Assistência Social. Essa foi concebida para ser operacionalizada como um sistema de proteção social com participação da sociedade. O problema é que esta participação, legal e socialmente falando, não deveria estar centrada no atendimento dos usuários da assistência Social.

Numa das diretrizes legais da Lei Orgânica consta que a primazia da responsabilidade pelo atendimento deve ser do Estado, conforme está previsto no artigo 5o, III da LOAS. A participação em massa da sociedade deveria ocorrer no controle social e na formulação das políticas públicas, como também determina o artigo 5으 II, da mesma Lei Orgânica.

Por essas contradições entre o propugnado e a prática realizada é que Yazbek (2004) questiona, em que medida esses anos de LOAS vem realizando direitos, à medida que o lugar da subalternidade, da exclusão social e do protagonismo de seus usuários tem sofrido mudanças.

Seguindo essa linha de análise dos elementos paradoxais entre a subalternidade e o protagonismo, seria interessante recuperar os ensinamentos de Gramsci, em que ele considera que a disputa da hegemonia deve implicar relações políticas com as classes subalternas, cujo desenvolvimento e transformações econômicas pressupõem adesão ativa ou passiva em relação às formações políticas dominantes, às lutas travadas a fim de 
influenciar tais políticas, além de criar uma agenda política na qual são apontadas reivindicações próprias.

O embate girava em torno da conquista da hegemonia, a ser obtida no âmbito da sociedade civil. Esta estratégia, denominada por Gramsci "guerra de posição", encerra em si um processo de luta para a conquista da direção político-ideológico e do consenso dos setores mais expressivos da população como caminho para conquista e conservação do poder (SIMIONATTO, 2011, p. 46).

Misturados aos interesses difusos, variando entre uma alternativa de ação complementar para alento da população e os interesses neoliberais de implementação de políticas sociais de compensação para apaziguamento do descontentamento popular, existe ainda outra questão relacionada à terceirização de serviços públicos: o interesse de um segmento da população de participar de ações solidárias pela ajuda do próximo. Como recusar esforços altruístas de uma entidade da rede privada e dizer-lhes que o melhor seria não existir, em face de tanta carência social no Brasil?

Essa vertente da questão é reconhecida como necessidade real e como uma estratégia de ampliação da capacidade de ação do Estado por Sposati et al. $(2012$, p. 88) ao problematizarem o progressivo repasse da execução dos serviços sociais para entidades sociais privadas:

No campo assistencial esta diretriz se faz inclusive como estratégia de capitalização dos esforços naturais de solidariedade social exercidos pelas organizações da sociedade civil. Os organismos estatais ao se responsabilizarem pelas ações de promoção social, não negarão, em absoluto, os esforços de filantropia e solidariedade da sociedade.

As diferentes reflexões e pontos de vistas entre os autores do Serviço Social, que estudam a atuação do terceiro setor no campo da assistência social, também problematizam o quanto essa tem sido alvo da desresponsabilização do Estado ao legitimarem a atuação complementar das ações terceiro setor como necessárias.

O maior problema dessa estratégia se manifesta por meio do paradoxo de se tentar ampliar a ação no campo da assistência social, visando à universalização dos acessos, ao mesmo tempo que se delega a ação concreta a entidades desorganizadas, desqualificadas profissionalmente, com alta rotatividade de mão de obra técnica, que trouxe para uma 
realidade de atendimentos um retrocesso em termos teórico-práticos, apesar de todo avanço na discussão teórica.

O momento é de buscar compreender as vicissitudes das gestões e das atuações profissionais da rede privada de assistência social, cujo atendimento, por mais necessário e urgente que seja, não pode ser tomado como ação da sociedade civil na perspectiva de uma contra-hegemonia. Isto, entretanto, não desmerece a importância de suas intervenções na realidade, desde que destituídas de preconceitos, e que suas ações sejam qualificadas no escopo de suas interferências, podendo contribuir substancialmente na tentativa de equacionar as questões mais aviltantes na garantia dos direitos à proteção social.

Mas, não é possível desconsiderar nesta reflexão o dissenso que o tema da atuação do terceiro setor na rede privada de assistência social provoca entre os assistentes sociais. Análises de Behring e Boschetti (2009) apontam para a questão do ponto de vista da gestão e não do das necessidades diretamente dos usuários. Com acuidade chamam a atenção para o fato de os agentes do chamado terceiro setor, os promotores privados de bem-estar social, ao substituírem a ação direta e o comando das políticas públicas do Estado, promoverem uma consequência política importante em termos neoliberais, que as autoras entendem como retrocesso político, conforme se pode observar:

\footnotetext{
Por não se constituir como uma rede complementar, mas assumir a condição de "alternativa eficaz" para viabilizar o atendimento das necessidades, esse apelo ao "terceiro setor" ou à "sociedade civil", aqui mistificada, configurou-se como um verdadeiro retrocesso histórico (BEHRING; BOSCHETTI, 2009, p. 162).
}

A crítica das referidas autoras volta-se à decomposição do sistema integrado para proteção social como de fato previsto na LOAS, entendendo que a atuação da rede privada no atendimento a usuários de assistência social é mais uma, dentre muitas estratégias, para a redução dos direitos e para a transformação neoliberal das políticas sociais, que se tornam "ações pontuais e compensatórias" direcionadas para os efeitos mais perversos da crise do capital, aniquilando a possibilidade de prevenção e passando à perspectiva de "correção dos efeitos".

No aspecto de gestão da política pública de assistência para alcance de metas de transformação social, a terceirização dos serviços de "atendimento" de assistência social, 
ainda na concepção de Behring e Boscheti (2009), são vistas como obstáculos e redirecionamento das conquistas da Constituição Federal de 1988 numa clara estratégia de contrarrevolução, já que um eventual inconformismo de grande parte dos trabalhadores e eleitores brasileiros tem sido sufocados com medidas capazes de tratamento pontual da questão social.

A rigor, esse debate não é novo, posto que tem sido discutido desde o começo dos anos 2000, quando se problematizava a descentralização, o que Yazbek (2004) identifica como a motivação do ingresso das entidades sem fins lucrativos na rede privada na assistência social. Defendia-se que a descentralização contribuiria para o reconhecimento das particularidades e interesses específicos dos municípios e aproximaria os serviços da população.

Behring e Boschetti (2009, p. 156) analisam que a descentralização fez parte do trinômio neoliberal, que:

[...] estabelecida como não compartilhamento de poder entre esferas públicas, mas como mera transferência de responsabilidade para entes da federação ou para instituições privadas e novas modalidades jurídico-institucionais correlatas, componente fundamental da "reforma" e das orientações dos organismos internacionais para a proteção social.

Já Montaño (2010, p. 152) é bastante radical em relação às atividades e intenções do terceiro setor, seja qual for sua frente de atuação:

[...] o debate o "terceiro setor" desenvolve certas manifestações que se põem como promessas de uma vida melhor. Estas soam, aos ouvidos dos autores, defensores e alguns membros do "terceiro setor", como um canto de sereia... que nos seduz e nos chama irreflexivamente para as obscuras profundezas do mar.

Montaño (2010) entende ainda que a real intenção das instituições privadas sem fins lucrativos não seria a de simplesmente "compensar" os efeitos nocivos da dominação capitalista; não seria apenas o instrumento de apaziguamento do descontentamento popular. Entende o autor que a parceria público-privada em qualquer dimensão seria para "encobrir e gerar aceitação da população" numa função ideológica concernente à reestruturação do capital. 
Dessa perspectiva, as instituições da rede privada de assistência poderiam estar tomando parte da construção ideológica capitalista por meio da consolidação da perspectiva hegemônica neoliberal, tornando o Estado cada vez mais "mínimo" para a população. Nesse caminho, abre espaço para a "criação de um vasto número de ONGs cujo objetivo central, senão único, é a própria captação desses recursos (fundraising) e a geração de (auto-) emprego" (MONTAÑO, 2010, p. 224).

O debate sobre o terceiro setor coloca perspectivas distintas de luta contrahegemônica ao neoliberalismo no campo da assistência social. Resgatando a contradição, Euzéby (2011) discorre, em obra organizada por Sposati (2011), com simpatia à participação das ONGs nas políticas públicas, fazendo referência à sua atuação como uma estratégia "com boas expectativas" utilizada na Europa e consolidada no tratado de Amsterdã, na luta contra a pobreza e a exclusão, baseada no princípio de cooperação para promover o crescimento econômico e durável, criar empregos e reduzir os riscos de pobreza e de exclusão e de reforçar a coesão social.

\section{Conclusão}

Ao longo de toda esta reflexão que se buscou analisar a natureza das atuais entidades assistenciais em seus aspectos legais e políticos, relacionados ao financiamento público, foi possível observar que a iniciativa privada pode se constituir de fato uma opção para o desenvolvimento e o fortalecimento de políticas democráticas e de garantia de direitos de cidadania e não simples estratégias políticas de contornos neoliberais.

Entretanto, para que suas atividades se constituíssem realmente em mecanismos de construção de uma cultura genuinamente democrática, deveriam desenvolver ações consistentes, articuladas e organizadas em sistemas de rede que oferecessem retaguardas complementares e ações emergenciais de apoio às ações do Estado.

Reconhece-se que, em face da imensa demanda social por assistência social, os municípios se veem forçados a buscar apoio para as necessidades sociais de amplo contingente populacional de necessitados nas ONGs voltadas aos atendimentos assistenciais, seja com dotações orçamentárias do próprio Estado, seja com recursos de outras organizações como de fundações, seja de organismos internacionais, seja de 
instituições internacionais de fomento ao desenvolvimento humano, seja mesmo de empresas privadas.

Observa-se que a forma como tais entidades estão sendo demandadas pelo próprio Estado está sendo recolocada em outros termos e com nova roupagem, a antiga prática social e cultural de atenção aos pobres por meio da caridade e do financiamento de entidades filantrópicas. Nesse sentido, fica evidenciado que uma das resultantes do processo prático dos últimos anos, que pode ser apreendida do debate teórico, é que o resultado político tem sido a manutenção do caráter tradicional das ações do Estado, apesar de todo avanço histórico consolidado na legislação da assistência social.

Nesse sentido, observa-se que os embates sobre as formas de condução das políticas assistenciais recolocam questões políticas e ideológicas conservadoras mais gerais, as quais têm sido fundamentais para a consolidação do projeto neoliberal no Brasil.

O desafio da construção de um sistema democrático de assistência social no Brasil ainda é muito grande e muito ainda precisa ser feito para se consolidar um sistema de proteção social que possa ultrapassar os interesses imediatos de embates eleitorais por disputa de poder.

\section{Referências}

BEHRING, E. R.; BOSCHETTI, I. Política social fundamentos e história. São Paulo: Cortez, 2009.

BRASIL. Constituição (1988). Constituição da República Federativa do Brasil: promulgada em 5 de outubro de 1988. Disponível em: <http://www.planalto.gov.br/ccivil_03/ constituicao/constituicaocompilado.htm>. Acesso em: 7 dez. 2013.

. Decreto 200, de 25 de fevereiro de 1967. Dispõe sobre a organização da Administração Federal, estabelece diretrizes para a Reforma Administrativa e dá outras providências. 1967. Disponível em: <http://www.planalto.gov.br/ccivil_03/decretolei/del0200.htm>. Acesso em: 25 out. 2013.

Lei 8.666, de 21 de junho de 1993. Regulamenta o art. 37, inciso XXI, da Constituição Federal, institui normas para licitações e contratos da Administração Pública e dá outras providências. 1993a. Disponível em: <http://www.planalto.gov.br/ccivil_03/ leis/ I8666cons.htm>. Acesso em: 7 ago. 2013.

Lei 8.742, de 07 de dezembro de 1993. Dispõe sobre a organização da Assistência Social e dá outras providências. 1993b. Disponível em: <http://www.planalto.gov.br/ 
. Lei 10.406, de 10 de janeiro de 2002. Institui o Código Civil. 2002a. Disponível em: <http://www.planalto.gov.br/ccivil_03/leis/2002/I10406.htm>. Acesso em: 5 set. 2013.

Ministério da Fazenda. Receita Federal. Resolução 247, de 26 de novembro de 2002. Dispõe sobre a Contribuição para o PIS/Pasep e a Cofins, devidas pelas pessoas jurídicas de direito privado em geral. 2002b. Disponível em: <http://www.receita.fazenda.gov.br/ Legislacao/ ins/2002/in2472002.htm>. Acesso em: 9 set. 2013.

Resolução 145, de 15 de outubro de 2004. Aprova a Política Nacional de Assistência Social. 2004. Disponível em: <http://www.mds.gov.br/assistenciasocial/ arquivo/Politica\%20Nacional\%20de\%20Assistencia\%20Social\%202013\%20PNAS\%202004 \%20e\%202013\%20NOBSUAS-sem\%20marca.pdf>. Acesso em: 17 set. 2013.

. Resolução 130, de 15 de julho de 2005. Aprova a Norma Operacional Básica da Assistência Social - NOB/SUAS. 2005. Disponível em: <http://www.mds.gov.br/acesso-ainformacao/legislacao/assistenciasocial/resolucoes/2005/Resolucao\%20CNAS\%20n o\%20130-\%20de\%2015\%20de\%20julho\%20de\%202005.pdf/view>. Acesso em: 1 out. 2013.

Lei 12.101, de 27 de novembro de 2009. Dispõe sobre a certificação das entidades beneficentes de assistência social; regula os procedimentos de isenção de contribuições para a seguridade social; altera a Lei $n$ - 8.742 , de 7 de dezembro de 1993; revoga dispositivos das Leis nos 8.212, de 24 de julho de 1991, 9.429, de 26 de dezembro de 1996, 9.732, de 11 de dezembro de 1998, 10.684, de 30 de maio de 2003, e da Medida Provisória no 2.187-13, de 24 de agosto de 2001; e dá outras providências. 2009a. Disponível em: <http://www.planalto.gov.br/ccivil_03/_ato20072010/2009/lei/l12101.htm>. Acesso em: 27 nov. 2013.

Lei 9.790, de 23 de março de 2009. Dispõe sobre a qualificação de pessoas jurídicas de direito privado, sem fins lucrativos, como Organizações da Sociedade Civil de Interesse Público, institui e disciplina o Termo de Parceria, e dá outras providências. 2009b. Disponível em: <http://www.planalto.gov.br/ccivil_03/leis/I9790.htm>. Acesso em: 18 ago. 2013.

Resolução 109, de 11 de novembro de 2009. Aprova a Tipificação Nacional de Serviços Socioassistenciais. 2009c. Disponível em: <http://www.mds.gov.br/acesso-ainformacao/legislacao/assistenciasocial/resolucoes/2009/Resolucao\%20CNAS\%20no\%20 109-\%20de\%2011\%20de\%20novembro\%20de\%202009.pdf>. Acesso em 18 out. 2013.

Ministério do Desenvolvimento Social e Combate à Fome - MDS. Censo SUAS 2010. Rede Privada, 2010a. Disponível em:<http://aplicacoes.mds.gov.br/sagi/ censo/suas/blog/?tag=arquivos-rede-privada>. Acesso em: 15 out. 2013

. Resolução 16, de 05 de maio de 2010. Define os parâmetros nacionais para a inscrição das entidades e organizações de assistência social, bem como dos serviços, programas, projetos e benefícios socioassistenciais nos Conselhos de Assistência Social dos Municípios e do Distrito Federal. 2010b. Disponível em: <http://www.mds.gov.br/acesso-ainformacao/legislacao/assistenciasocial/resolucoes/ 2010/Resolucao\%20no16-2010/view>. Acesso em: 21 nov. 2013. 
Resolução 27, de 19 de setembro de 2011. Caracteriza as ações de assessoramento e defesa e garantia de direitos no âmbito da Assistência Social. 2011. Disponível em: <http://www.legisweb.com.br/legislacao/?id=115637>. Acesso em: 12 nov. 2013.

CONSELHO NACIONAL DE ASSISTÊNCIA SOCIAL. Relatório da IV Conferência de Assistência Social. 2003. Disponível em:

<file:///C:/Users/Usuario/Downloads/Relat\%C3\%B3rio\%20Final\%20-

\%20IV\%20Confer\%C3\%AAncia\%20Nacional.pdf>. Acesso em: 2 set. 2013.

Euzéby, C. IN: SPOSATI, A. O. (Org.). Proteção Social de Cidadania: inclusão de idosos e pessoas com deficiência no Brasil, França e Portugal. São Paulo: Cortez, 2011.

MONTAÑO, C. Terceiro setor e questão social: crítica ao padrão emergente de intervenção social. 6. ed. São Paulo: Cortez, 2010.

SIMIONATTO, I. Gramsci sua teoria, incidência no Brasil, influência no serviço social. 4. ed. São Paulo: Cortez, 2011.

SPOSATI, A. O. (Org.). Proteção Social de Cidadania. São Paulo: Cortez, 2011.

SPOSATI, A. O. et al. Assistência na trajetória das políticas sociais brasileiras: uma questão de análise. 11. ed. São Paulo: Cortez, 2012.

YAZBEK, M. C. As ambiguidades da Assistência Social brasileira após dez anos de LOAS. Serviço Social e Sociedade, São Paulo, ano 25, n. 77, p. 11-29, mar. 2004.

Recebido em: 26/02/2014

Aprovado em: $15 / 05 / 2014$ 